\title{
Adapting clonally propagated crops to climatic changes: a global approach for taro (Colocasia esculenta (L.) Schott)
}

\author{
V. Lebot $\cdot$ V. Tuia $\cdot$ A. Ivancic $\cdot$ G. V. H. Jackson $\cdot$ F. Saborio $・$ \\ G. Reyes $\cdot$ S. Rodriguez $\cdot$ G. Robin $\cdot$ R. Traoré $\cdot$ L. Aboagye $\cdot$ J. Onyeka $\cdot$ \\ W. van Rensburg $\cdot$ V. Andrianavalona $\cdot$ A. Mukherjee $\cdot$ M. S. Prana • \\ D. Ferraren - B. Komolong $\cdot$ F. Lawac $\cdot$ S. Winter $\cdot$ M. A. A. Pinheiro de Carvalho \\ T. Iosefa
}

Received: 18 April 2017 / Accepted: 23 August 2017/Published online: 5 September 2017

(C) Springer Science+Business Media B.V. 2017

\begin{abstract}
Clonally propagated crop species are less adaptable to environmental changes than those propagating sexually. DNA studies have shown that in all countries where taro (Colocasia esculenta (L.) Schott) has been introduced clonally its genetic base is narrow. As genetic variation is the most important source of adaptive potential, it appears interesting to attempt to increase genetic and phenotypic diversity to strengthen smallholders' capacity to adapt to climatic changes. A global experiment, involving 14 countries
\end{abstract}

V. Lebot $(\square)$

UMR AGAP, CIRAD, PO Box 946, Port-Vila, Vanuatu

e-mail: lebot@vanuatu.com.vu

V. Tuia

SPC, Suva Regional Office, Private Mail Bag, Suva, Fiji

\section{A. Ivancic}

University of Maribor, Pivola 10, 2311 Hoče, Slovenia

G. V. H. Jackson

PestNet, Sydney, NSW 2022, Australia

F. Saborio

Centro de Investigaciones Agronómicas, University of

San José, San José, Costa Rica

G. Reyes

University of Managua, PO Box 453, Managua,

Nicaragua

S. Rodriguez

INIVIT, Apartado 6, Santo Domingo, 53000 Santa Clara, Cuba from America, Africa, Asia and the Pacific was conducted to test this approach. Every country received a set of 50 indexed genotypes in vitro assembling significant genetic diversity. After onstation agronomic evaluation trials, the best genotypes were distributed to farmers for participatory on-farm evaluation. Results indicated that hybrids tolerant to taro leaf blight (TLB, Phytophthora colocasiae Raciborski), developed by Hawaii, Papua New Guinea and Samoa breeding programmes outperformed local

G. Robin

CARDI, St Vincent, Trinidad and Tobago

R. Traoré

Université de Ouagadougou, 03 BP 7021, Ouagadougou, Burkina Faso

L. Aboagye

Plant Genetic Resources Research Institute, CSIR, PO Box 7, Bunso, Ghana

J. Onyeka NRCRI, Umudike, Umuahia PMB 7006, Abia State, Nigeria

W. van Rensburg

ARC, Roodeplaat, Privet Bag X293, Pretoria 0001, South Africa

V. Andrianavalona FOFIFA-CENRADERU, Antananarivo, Madagascar 
cultivars in most locations. However, several elite cultivars from SE Asia, also tolerant to TLB, outperformed improved hybrids in four countries and in one country none of the introductions performed better than the local cultivars. Introduced genotypes were successfully crossed (controlled crossing) with local cultivars and new hybrids were produced. For the first time in the history of Aroids research, seeds were exchanged internationally injecting tremendous allelic diversity in different countries. If climatic changes are going to cause the problems envisaged, then breeding crops with wide genetic diversity appears to be an appropriate approach to overcome the disasters that will otherwise ensue.

Keywords Allelic diversity - Colocasia esculenta . Crossing · In vitro distribution · On-farm evaluation · Selection

\section{Introduction}

There are uncertainties regarding regional climate change prediction models (Ramirez-Villegas et al. 2013). Hence, the development of strategies aiming at strengthening smallholders' adaptation to climatic changes is problematical and the identification of breeding objectives for the creation of new varieties is challenging. The situation for clonally propagated crop species is quite complex as they are less adaptable to changes in environmental conditions than those propagating sexually (Dodd and Douhovnikoff 2016; Mercer and Perales 2010). As far as tropical root and tuber crops (cassava, sweet potato, yams and aroids) are concerned, smallholders in

\footnotetext{
A. Mukherjee

CTCRI, Sreekariyam, Thiruvananthapuram,

Kerala 695 017, India
}

M. S. Prana

LIPI, Cibinong km 42, Bogor, Java, Indonesia

D. Ferraren

Visayas State College of Agriculture, PhilRootCrops, 6251-A Baybay, Leyte, Philippines

B. Komolong

NARI, PO Box 4415, Lae, Morobe Province,

Papua New Guinea developing countries cannot rely on organized breeding programmes or national seed supply systems to renew their germplasm. The vast majority rely on their own cultivars (landraces) obtained through local selection and traditional exchanges. As the development of a new variety takes about 10 years without guarantee of wide adoption, there is a need to find alternative ways of accelerating smallholders' adaptation capacity (Ceballos et al. 2015).

Studies conducted with DNA markers revealed that for most of these roots and tuber crop species, genetic distances correspond to geographic distances and there are different genepools. Markers also revealed that new variants spontaneously appearing in farmers' plots are hybrids (Scarcelli et al. 2006). In practice, farmers intercrop different genotypes which may flower, genetically recombine and produce viable seeds that germinate and the most attractive volunteers are cloned (Roullier et al. 2013). These new variants are then tested and if they satisfy farmers' needs, they are exchanged with others (Sardos et al. 2012). This suggests that farmers can manipulate germplasm if they have access to sufficient allelic diversity. Traditional networks between communities can then distribute clones efficiently through family ties (VandenBroucke et al. 2015).

Taro (Colocasia esculenta (L.) Schott) is a neglected root crop and an "orphan" species with no international research centre with the mandate to assist producers with the development of improved varieties (unlike cassava, sweet potato and yams). It has, however, a recognized potential to strengthen food security. It has been grown in tropical Asia for more than 10,000 years (Fullagar et al. 2006) and is now cultivated throughout the wet tropics (Matthews et al. 2017). According to FAO databases, taro produce the

F. Lawac

VARTC, PO Box 231, Luganville, Santo, Vanuatu

S. Winter

DSMZ, Leipzig, Messeweg 11/12, 38104 Braunschweig, Germany

M. A. A. Pinheiro de Carvalho IsoPlexis Genebank, University of Madeira, 9000-390 Funchal, Madeira, Portugal

T. Iosefa

SPC, Alafua Campus, Apia, Samoa 
lowest yields of all root crops, with an average of only 6.5 tons of fresh corms per ha. In most countries, taro is either a backyard or home garden crop, or is cultivated by smallholders within a shifting agroforestry system with very limited inputs. The world production in 2014 was approximately 11 million tons of fresh corms and cormels from 1.5 million ha but many countries do not maintain or supply statistics for taro (e.g., India, Bangladesh, Burma, Indonesia, Vietnam, Cuba and others) although they are significant producers. The highest yields $(>20 \mathrm{t} / \mathrm{ha})$ are obtained in subtropical zones (Egypt, China) (www. fao.org 2014).

The genetic diversity of taro has been well documented. The study of the isozyme variation in more than 1400 cultivars (diploids and triploids) and wild forms from Asia and Oceania revealed greater variation in Asia (Lebot and Aradhya 1991). Isozymes and ribosomal DNA were useful to study the variation in cultivars from China, Taiwan and Japan (Matsuda 2002). AFLP markers have confirmed that diversity is greater in Asia but that the genetic diversity within most countries is low (Kreike et al. 2004). More recently, SSRs were used to investigate diversity in 19 countries of Asia, the Pacific, Africa and America. The highest diversity was again observed in Asia, mainly in India, and clonal reproduction appeared predominant in African and American countries. In West Africa, cultivars were found to have originated from India while in South Africa cultivars shared lineages with Japan. Surprisingly, cultivars from the West Indies were found to have originated from the Pacific, while in Costa Rica they were from India or Asia. To sum up, in all countries where taro has been introduced clonally, its genetic base is narrow (Chaïr et al. 2016).

Producing crops ready for change-changes to climate, pests and diseases or a need for processingis particularly difficult for those that are vegetatively propagated and where seed propagation requires special procedures. As genetic variation is the most important source of adaptive variation, it appears interesting to attempt to increase taro genetic variation within smallholders' portfolios. We can expect farmers to use it to adapt to climatic changes. This could be achieved through the geographical distribution of allelic diversity and through the distribution of selected genotypes. A core sample representing the useful diversity of the species has been assembled with the best cultivars from South East Asia (Lebot et al.
2004). It would therefore be interesting to distribute these elite genotypes for direct use or for breeding to countries with narrow genetic bases. Breeding programmes in Papua New Guinea (PNG), Samoa and Hawaii have produced taro hybrids tolerant to the taro leaf blight (TLB, Phytophthora colocasiae Raciborski) and the distribution of these could also contribute to strengthen smallholders' adaptation. Finally, segregating progenies obtained from true botanical seeds resulting from controlled crosses between selected parents could be distributed directly to farmers to allow farmers' selection of hybrids corresponding to local needs. Consequently, taro appears as a good model species to study how allelic diversity could be injected in farmers' fields through the propagation, distribution and on-farm evaluation of selected genotypes introduced following international guidelines for the safe movement of germplasm (Zettler et al. 1989).

We conducted a global experiment to compare the performances of taro cultivars and improved hybrids distributed to farmers in 14 different countries of Asia, Africa, America and the Pacific. We present here the results obtained for the research stations propagation process and agronomic evaluation, the on-farm evaluation of introduced germplasm and the first attempts to cross introduced genotypes with local cultivars. We also discuss the practicalities of this approach for taro and its potential for adapting other root and tuber crops to climatic changes.

\section{Materials and methods}

\section{Selected genotypes}

The geographical origins and major characteristics of cultivars and hybrids distributed and evaluated in this study are presented in Table 1. Fifty-nine cultivars originated from: Indonesia (21), Japan (6), Malaysia (9), the Philippines (2), Thailand (20) and Vietnam (1) were considered. They correspond to some of the best farmers' varieties selected in each country by the Taro Network for South East Asia and Oceania (TANSAO) (Kreike et al. 2004). Forty-one hybrids originated from: the University of Hawaii breeding programme (6), the NARI (National Agricultural Research Institute) breeding programme in PNG (8) and the Secretariat of the Pacific Community breeding 


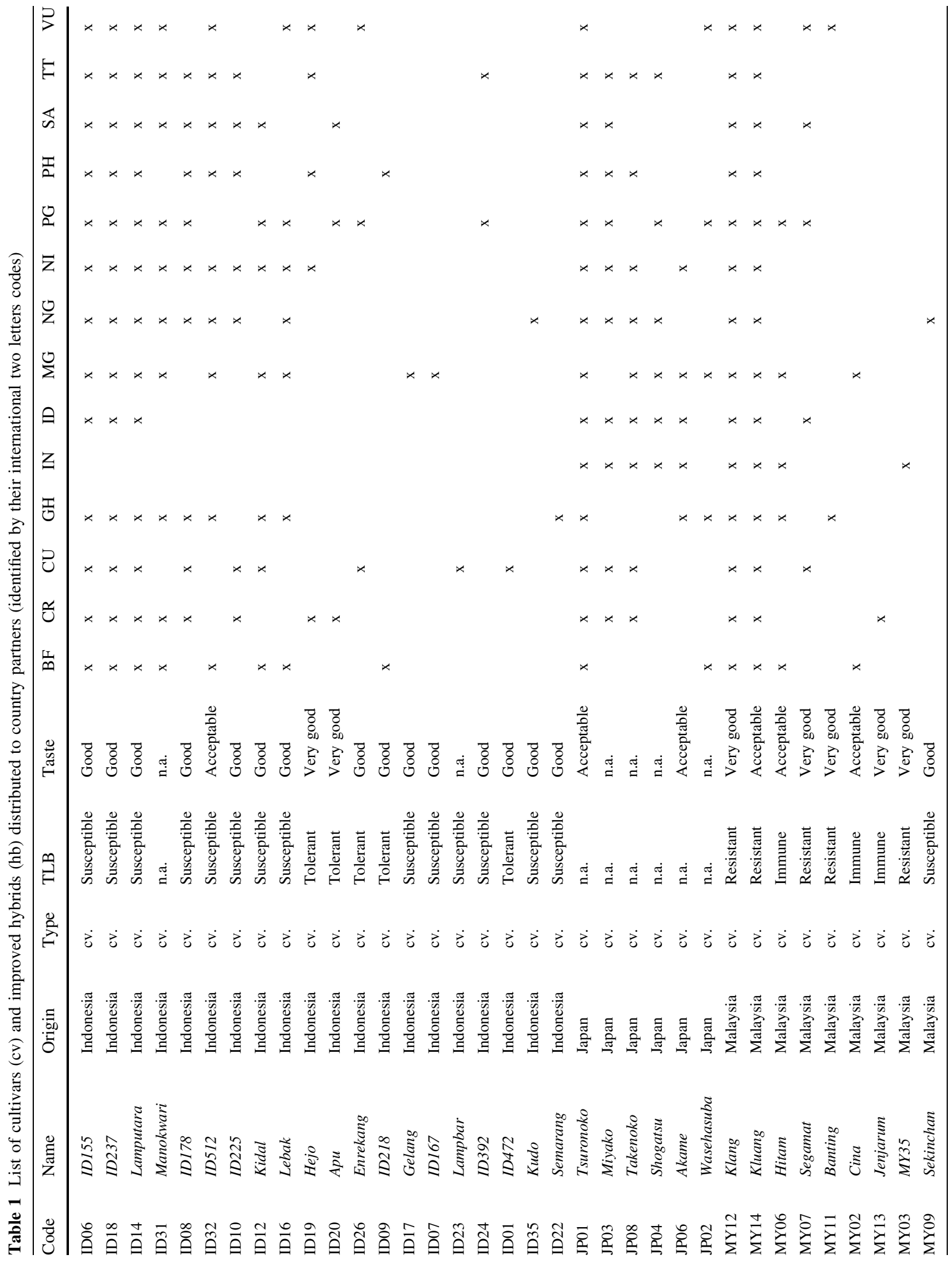




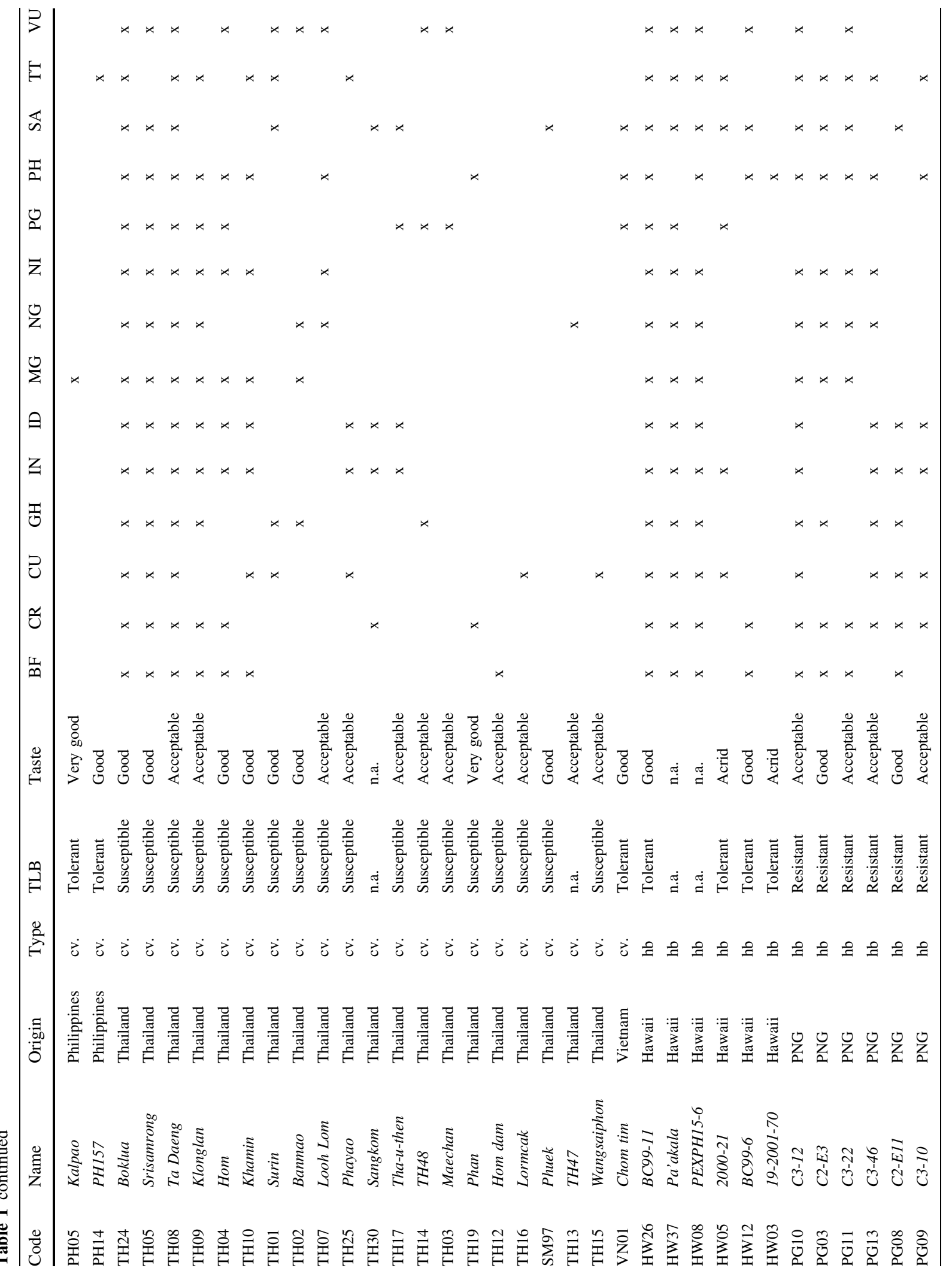




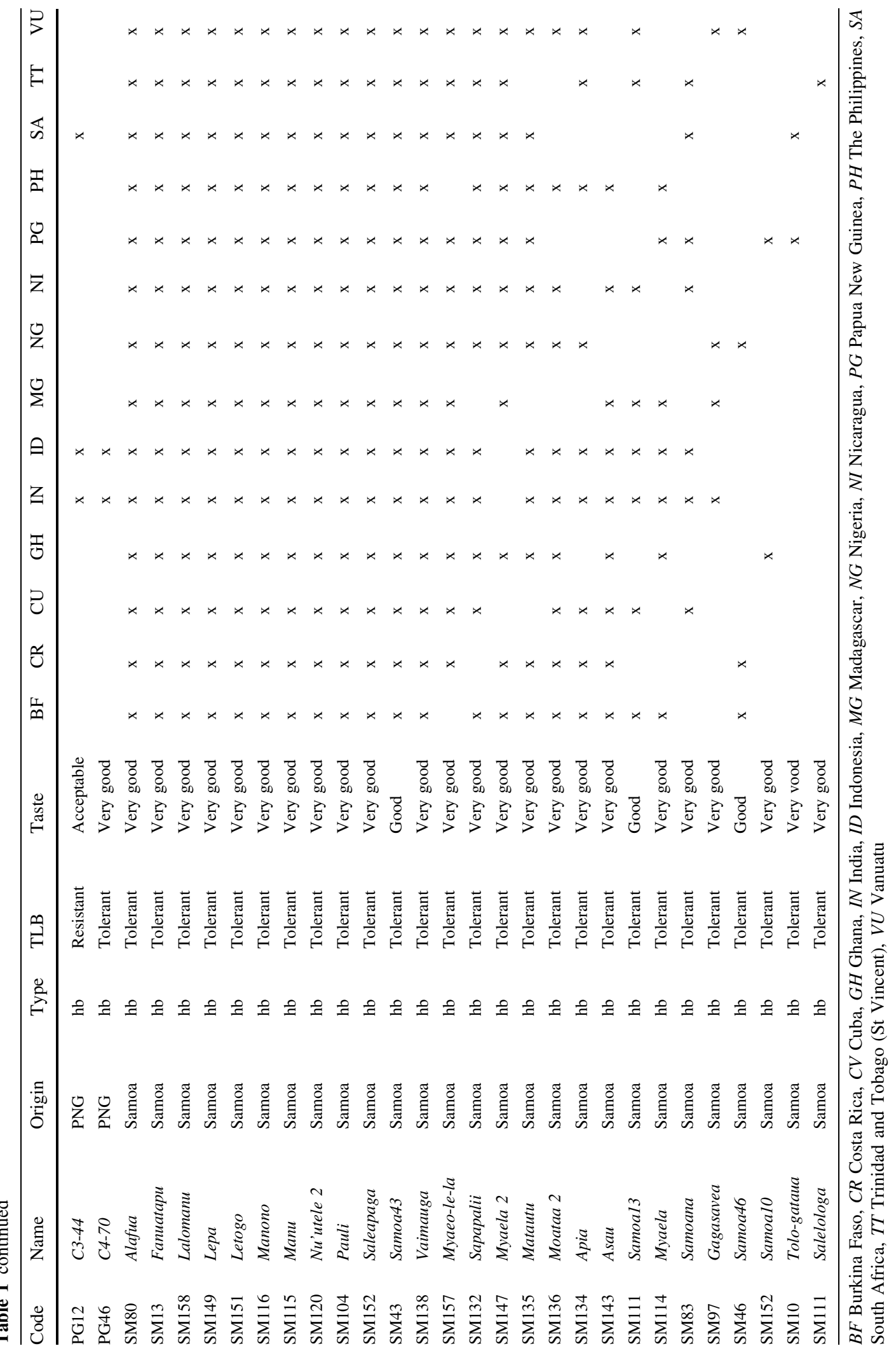


programme in Samoa (27). All hybrids were obtained through controlled crosses and successive recurrent selection cycles. Overall, 100 genotypes were selected for their geographical distances and genetic diversity, their corm shape and quality, and their tolerance or resistance to TLB (Table 1).

Indexation of germplasm

All taro accessions were maintained in vitro in the Pacific Community (SPC) Centre for Pacific Crops and Trees, Suva, Fiji. Tissue cultured accessions were grown in $100 \mathrm{~mL}$ glass jars (Cospak, Australia), containing $20 \mathrm{~mL}$ of Murashige and Skoog basal medium, supplemented with $3 \%$ sucrose, benzylaminopurine $(1.0 \mathrm{mg} / \mathrm{L})$ and naphthalene-acetic acid $(0.3 \mathrm{mg} / \mathrm{L})$. Cultures were maintained at a temperature of $20{ }^{\circ} \mathrm{C}$ under a day length of $16 \mathrm{~h}$ (Taylor 2002). In vitro plantlets were raised from parent plants which were inspected, screened and found to be free from $P$. colocasiae. Further, the taro plantlets were derived from mother plants which have been indexed negative at three, and again at 6 months of growth, for each of the four known taro viruses (Dasheen mosaic virus, Taro bacilliform virus, Taro vein chlorosis virus, and Colocasia bobone disease virus) using highly sensitive polymerase chain reaction, with both negative and positive controls included in all tests. Only suckers derived in vitro from an original meristem, which was tested negative for viruses, were considered as negative for those viruses. These suckers were used to provide the source from which all clones of selected genotypes were obtained. The virus indexing protocol used was developed by Queensland University of Technology in Australia under the AusAID-funded Taro Genetic Resources: Conservation and Utilization project (1998-2003) (Harding et al. 2004).

\section{International distribution}

Between June and November 2011, 50 genotypes (three in vitro clones per genotype) were sent to 14 different country partners: Costa Rica (University of Costa Rica, San José), Nicaragua (University of Nicaragua, Managua), Cuba (INIVIT, Instituto Nacional de Investigaciones de Viandas Tropicales, Santa Clara), St Vincent (CARDI, Caribbean Agricultural Research and Development Institute, Trinidad and Tobago), Burkina Faso (Université de Ouagadougou),
Ghana (CSIR, Plant Genetic Resources Research Institute), Nigeria (NRCRI, National RootCrops Research Institute, Umudike), South Africa (ARC, Agricultural Research Council, Pretoria), Madagascar (FOFIFA, Centre National de la Recherche Appliquée au Développement Rural, Antananarivo), India (CTCRI, Central Tuber Crops Research Institute, Trivandrum), Indonesia (LIPI, Indonesian Centre for Research and Development in Biotechnologies, Bogor), the Philippines (PhilRootCrops, Baybay, Leyte), Papua New Guinea (NARI, National Agricultural Research Institute, Lae), Vanuatu (VARTC, Vanuatu Agricultural Research Training Centre, Santo). Expeditions were done as soon as an import permit was signed by the authorized official institution in the importing country partners. Distributions from SPC to the partners were made under the Standard Material Transfer Agreement of the International Treaty on Plant Genetic Resources for Food and Agriculture.

On-station propagation and evaluation

Upon receipt, all country partners transferred the introduced in vitro plantlets into nurseries. The plastic pots were filled with a compost/soil mix sterilized with good drainage and aeration. The plantlets roots were washed thoroughly to completely remove the culture medium containing nutrients and sugar which attract fungi and bacteria. The plantlets were then covered with clear plastic bag without holes for the first 4 weeks to maintain high humidity and help the plants to adjust to their new environment. After 4 weeks, the plastic bags were gradually removed. Developing plants were watered three or four times a week on alternative days depending on the weather and screen house conditions. Field propagation was initiated in 2012. During 2 years, plants of selected varieties were intensively propagated on-station (through headsets corresponding to the summit of the corm and/or suckers). During the propagation and on-station evaluation process, local cultivars were used for comparison with introduced genotypes. Local and introduced genotypes were planted at $1 \times 1 \mathrm{~m}$ spacing. The local checks were the best local cultivars identified in each participating country during the previous years of characterization of national germplasm collections. A range of qualitative and quantitative morphological and agronomic data were collected as part of the 
evaluations; these included, stolon and sucker production, flowering ability, vigour, plant height, TLB tolerance and corm yield. Five plants per genotype were scored during two successive years before selecting the most interesting genotypes for further propagation.

\section{Production of true taro seeds}

Partners produced controlled crosses following protocols described in details elsewhere (Ivancic and Lebot 2000). Briefly, emasculation was conducted 2 days before the inflorescence opened by cutting the upper part of the spathe and the whole male portion of the spadix. After pollination, female flowers were protected with the lower green part of the spathe which was removed during emasculation. Fruit heads were usually ready to be harvested 1 month after pollination. Seeds can be germinated 1 week after sowing and/or can be kept for several years in a glass flask or ziplock plastic bag with silica gel in deep freeze. In each country, the best parents were selected after onstation evaluation, crosses were made and seeds were collected and germinated. In Vanuatu and PNG, seeds obtained from open pollination between selected hybrids, were collected and bulked. In June-July 2015, these seeds were distributed to all partners and germinated upon reception. Seedlings were raised in nurseries and hybrid plants in their first clonal generation were distributed to farmers for screening, each farmer receiving only one clone per hybrid in batches of 30 hybrids (Fig. 1).

\section{On-farm evaluation}

Genotypes for on-farm trials were selected primarily on yield performance. All introduced genotypes producing 10 and more t/ha (more than $1 \mathrm{~kg} / \mathrm{plant}$ ) were included in the list for on-farm trials. In order to increase genetic diversity in farmer fields, the best and popular local varieties were not included even though they produced good yield because they were already quite widespread in farmer's fields. Although, several local cultivars produced yields between 4 and $9 \mathrm{t} / \mathrm{ha}$, preference was always given to exotic genotypes that showed high or moderate levels of resistance to TLB and had good eating qualities. A total of 30 accessions were selected for on-farm trials. In mid-2014, headsets of selected genotypes were distributed to farmers for evaluation. Depending on the number of headsets available and on the number of volunteer farmers, the number of sites (villages) varied per country partner (Table 2). At harvest, corms were weighted and farmers were invited to taste their organoleptic characteristics following the most common cooking preparation: peeling, washing, cutting into pieces of approximately $5 \times 5 \mathrm{~cm}$ and boiling in water. Farmers were invited to score each genotype (cultivar or hybrid) for taste, texture, aroma and acridity on a scale from 1 (poor) to 5 (excellent) without being replicated.

\section{Results}

Due to insufficient availability of indexed in vitro plantlets, partners received different sets of cultivars and hybrids. However, 18 genotypes including cultivars from Japan (JP01), Malaysia (MY12, MY14), Thailand (TH24, TH08) and hybrids from Hawaii (1), and Samoa (12) were distributed to 14 country partners and 33 genotypes were common to 10 countries (Table 1). Each of the 14 participating countries received cultivars and hybrids from different geographical origins. Cultivars originating from Indonesia, Japan, Malaysia and Thailand had already been fingerprinted with isozymes and DNA markers (Lebot and Aradhya 1991; Kreike et al. 2004) to confirm their genetic distances and were distributed to all countries. Hybrids from the breeding programmes in Hawaii, PNG and Samoa were also distributed to all partners (of course, hybrids from PNG were not sent to PNG). These hybrids have been produced through crosses between TANSAO elite genotypes and local cultivars and were therefore highly heterozygous (Cho 2004; Iosefa et al. 2012). Overall, significant allelic diversity was therefore introduced in each country with 50 selected genotypes (Table 1).

The regional germplasm centre of SPC in Fiji has developed an efficient system for distribution of plants in plastic pouches (Taylor et al. 2004) and contamination rates were extremely low, and accordingly transfers to soil were highly successful. In most countries, the number of introduced genotypes evaluated on-station was high with rates of $100 \%$ in Costa Rica, the Philippines and Papua New Guinea. However, in three countries (Burkina Faso, Nigeria, Indonesia), the number of genotypes successfully evaluated on-station was lower and this was reported 
Fig. 1 A In vitro plantlets received by partners,

B transplanting young plants into plastic pots in nurseries, C on-station propagation plots after cyclone Haiyan in November 2013 in Baybay, Leyte, the Philippines, D field propagation of selected genotypes in Nicaragua, E preparing batches of headsets for distribution to farmers in the East Coast of Madagascar, F distribution of batches to farmers in Costa Rica, G discussing vegetative growth with farmers on the Highlands of Madagascar,

$\mathbf{H}$ harvesting on-farm trials in Morobe Province, Papua New Guinea, I cross pollinated fruit head in Santo, Vanuatu, J true botanical seeds ready for international exchange
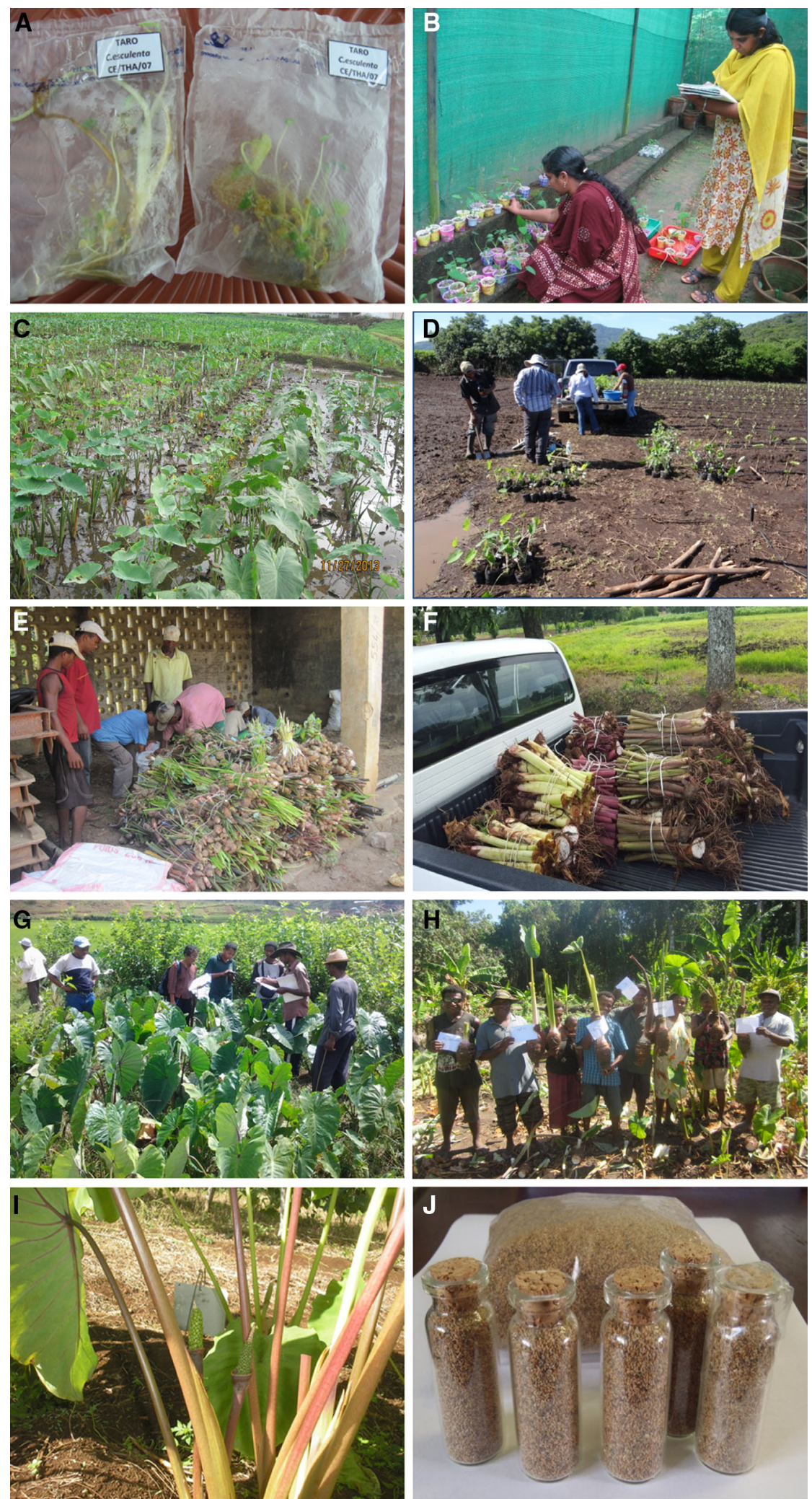
Table 2 Selected genotypes distributed to farmers for participatory evaluation

\begin{tabular}{|c|c|c|c|c|c|c|c|}
\hline Country & $\begin{array}{l}\text { Local cultivars } \\
\text { maintained on- } \\
\text { station }\end{array}$ & $\begin{array}{l}\text { Introduced } \\
\text { genotypes } \\
\text { evaluated on- } \\
\text { station }\end{array}$ & $\begin{array}{l}\text { Local cultivars } \\
\text { used for } \\
\text { comparison }\end{array}$ & $\begin{array}{l}\text { Genotypes } \\
\text { (cvs }+ \text { hbs) } \\
\text { selected on- } \\
\text { station }\end{array}$ & $\begin{array}{l}\text { Genotypes } \\
\text { distributed to } \\
\text { farmers }\end{array}$ & $\begin{array}{l}\text { On-farm } \\
\text { trials sites } \\
\text { (villages) }\end{array}$ & $\begin{array}{l}\text { Farmers } \\
\text { involved }\end{array}$ \\
\hline Costa Rica & 2 & 50 & 2 & 30 & 30 & 9 & 52 \\
\hline Nicaragua & 6 & 43 & 8 & 25 & 31 & 8 & 16 \\
\hline Cuba & 102 & 48 & 5 & 18 & 0 & 0 & 0 \\
\hline St Vincent & 2 & 45 & 2 & 9 & 30 & 8 & 25 \\
\hline Burkina Faso & 18 & 28 & 18 & 22 & 22 & 4 & 66 \\
\hline Ghana & 81 & 37 & 81 & 30 & 30 & 8 & 60 \\
\hline Nigeria & 5 & 25 & 5 & 9 & 9 & 4 & 50 \\
\hline South Africa & 81 & 49 & 29 & 15 & 20 & 4 & 10 \\
\hline Madagascar & 8 & 37 & 8 & 10 & 27 & 5 & 143 \\
\hline India & 424 & 37 & 3 & 37 & 35 & 12 & 52 \\
\hline Indonesia & 252 & 26 & 4 & 30 & 30 & 4 & 50 \\
\hline Philippines & 240 & 50 & 5 & 16 & 16 & 6 & 100 \\
\hline $\begin{array}{l}\text { Papua New } \\
\text { Guinea }\end{array}$ & 279 & 50 & 10 & 30 & 34 & 11 & 21 \\
\hline Vanuatu & 302 & 47 & 50 & 30 & 24 & 8 & 16 \\
\hline
\end{tabular}

to be due to poor adaptation observed at the nursery stage (Table 2). In 2012, several partners provided photographs of their nurseries and/or propagation plots and these have been posted on the International Network for Edible Aroids (INEA) website (www. ediblearoids.org). Overall, the in vitro introduction process was considered by all partners as fairly simple and technically easy to implement.

There were noticeable differences in the performance of the introductions, and the results from the evaluations, both on-station and in farmers' fields (Table 2). For instance, at the nursery stage, it soon appeared that Japanese genotypes were not adapted to the tropical conditions of most countries and their growth and yield measured on-station were too low to allow further field propagation. However, some of these Japanese cultivars presented good eating quality (observed in PNG) and good pollen fertility (observed in Cuba) and were therefore kept cautiously in germplasm collections and were used as parents in crosses. The number of local checks used during the on-station evaluation process varied from only two local cultivars (Costa Rica), whereas there were 50 in Vanuatu and 81 in Ghana. In Vanuatu and Ghana, introduced genotypes were planted and harvested together with the local germplasm collections, so that the introductions could be compared with a large number of local cultivars. In most countries, the onstation evaluation trials confirmed the superior performance of the introductions in terms of yield, vigour, TLB tolerance of the breeding lines from the Hawaii, PNG and Samoa breeding programmes. TLB has been introduced to western Africa and is now spreading very rapidly throughout this region (Omane et al. 2012). However, $P$. colocasiae is not a threat yet in Costa Rica, Nicaragua, Cuba, St Vincent, South Africa and Vanuatu but could be introduced anytime.

After 2 years of on-station evaluation, the number of selected genotypes (local or introduced cultivars and hybrids) ranged from nine in St Vincent and Nigeria to 37 in India. Taro farmers in St Vincent are focusing on the export market to the US. In this case, it was thought more appropriate to select on-station only those genotypes with traits corresponding to the local cultivar used to satisfy market demands; accordingly, only nine genotypes were selected for on-farm evaluation. The number of genotypes distributed to farmers ranged from 35 genotypes in India to zero in Cuba, where on-farm evaluation continues before distribution of selected genotypes through the national scheme. Hence, the number of distinct evaluation sites and farmers involved in on-farm trials varied greatly 
between countries. In Madagascar, for instance 143 farmers received selected genotypes for on-farm evaluation (Table 2).

After two successive years of on-farm evaluation trials, partners ranked their best five genotypes based on on-station and on-farm evaluation trials (Table 3). Hybrids from Hawaii breeding programme (HW nos) performed well in Costa Rica, Nicaragua, Cuba and Ghana. Hybrids from Samoa (SM nos) performed well in Burkina Faso, Madagascar, the Philippines and Vanuatu. One hybrid from PNG (PG03) performed well in Nigeria. Interestingly, introduced cultivars performed better than hybrids in St Vincent, South Africa, India and Indonesia. In Papua New Guinea, an improved hybrid from the fifth recurrent selection cycle (C5-353) outperformed introduced genotypes. However, in South Africa, none of the 50 introduced genotypes performed better than the local cultivars. Overall, in the 14 countries, 64 introduced genotypes (54 hybrids and 10 cultivars) were ranked in the five best genotypes and performed better than local taro cultivars.

Except for PNG, India and Vanuatu, in most countries, taro breeding was at a very early stage before this global experiment was initiated. Therefore, the introduction of genotypes aimed at introducing parents to produce local hybrids tolerant to TLB with good quality corms, and to distribute them to farmers to make adaptation to climatic changes possible. The results of the crosses conducted in participating countries between introduced genotypes and local cultivars are presented in Table 4. In Costa Rica, nine crosses were conducted and after evaluation of 90 seedlings, there are nine selected hybrids under further test in 2017. These are from crosses between local cultivars and hybrids from Samoa and Hawaii. Selections were made for low numbers of suckers and a large round main corm. In Cuba, considerable seedling variation has been produced from 23 successful hybridisations, using female parents from Thailand, Malaysia, Samoa and Japan. The cultivar Miyako (Japan) and the Samoa hybrid Manu (SM135) were found to be the best pollen donors.

In Burkina Faso, the best exotic genotypes used as parents were PG10, ID14, ID06, ID24, SM13, SM138 and TH12. More than 200 crosses were made, of which 96 were successful and the germination rate was $34 \%$. There are now selected 70 hybrids and these are being multiplied. In South Africa, flower induction of the local cultivars was successful but pollinations failed. Most of the local cultivars were found to be triploids (Chair et al. 2016). In future, the introduced genotypes will be used as female parents and the local ones as pollen donors. In Madagascar, hybridisations were attempted but the local cultivars did not flower, so crosses were made between introductions and between them and wild taro genotypes flowering naturally. As taro, has been introduced clonally with the first Austronesian migrations ca. 2000 years ago, these wild types are in fact escaped from cultivation and naturalised. Of the 60 crosses made, 37 came to maturity, and more than 20,000 seeds were sown. The
Table 3 Best five selected genotypes after two years of on-station evaluation (2012-14) and two years of on-farm evaluation (2015-16) (cultivars are in italics)

* On-station evaluation only

\begin{tabular}{llllll}
\hline Country & 1st & 2nd & 3rd & 4th & 5th \\
\hline Costa Rica & HW37 & SM46 & SM116 & SM128 & PG13 \\
Nicaragua & HW26 & PG03 & SM151 & SM158 & ID24 \\
Cuba* & HW37 & SM143 & C3-12 & SM128 & SM80 \\
St Vincent & ID24 & SM80 & SM149 & SM83 & PG09 \\
Burkina Faso & SM80 & SM135 & PG11 & HW05 & SM120 \\
Ghana & HW37 & SM151 & SM10 & ID24 & SM134 \\
Nigeria & PG03 & TH05 & SM158 & ID12 & SM80 \\
South Africa & Thandizwe & Amzam & Mabhida & Ngubane & Gumede \\
Madagascar & SM80 & SM115 & SM157 & SM43 & SM128 \\
India & ID06 & TH10 & TH07 & SM116 & SM151 \\
Indonesia & TH05 & Mentega & SM135 & SM157 & SM134 \\
Philippines & SM115 & SM151 & SM132 & SM80 & MY112 \\
Papua New Guinea & C5-353 & SM143 & SM148 & SM43 & C5-245 \\
Vanuatu & SM13 & SM138 & PG11 & SM149 & SM120 \\
\hline
\end{tabular}


Table 4 Summary results of crosses conducted between introduced and local genotypes

\begin{tabular}{llllll}
\hline Country & Parents selected & Crosses conducted & Seeds obtained & Seedlings transplanted & Selected local hybrids \\
\hline Costa Rica & 6 & 9 & 286 & 90 & 9 \\
Nicaragua & 6 & 3 & 0 & 0 & 0 \\
Cuba & 19 & 23 & 2037 & n.a. & n.a. \\
St Vincent & - & - & - & - & - \\
Burkina Faso & 38 & 205 & 22,365 & 7604 & 70 \\
Ghana & 12 & 12 & n.a. & 1680 & 12 \\
Nigeria & 14 & 22 & 7316 & 259 & 180 \\
South Africa & - & - & - & - & - \\
Madagascar & 19 & 60 & n.a. & $>20,000$ & 1053 \\
India & 12 & 10 & n.a. & 234 & 32 \\
Indonesia & 30 & - & n.a. & - & - \\
Philippines & 16 & 12 & n.a. & 1111 & n.a. \\
Papua New Guinea & 60 & 200 & n.a. & $>4000$ & 931 \\
Vanuatu & 22 & 18 & 2319 & 2040 & 242 \\
\hline
\end{tabular}

seedlings (7604) are still under evaluation on the East coast lowlands (Ilaka research station). In addition, seeds were obtained from Vanuatu in 2015. More than 5000 seedlings were raised and 1790 given to ten farmers and 800 planted on-station on the East coast. In Ghana, twelve successful hybridizations resulted from crosses between ten introduced genotype and two local cultivars. A total of $1680 \mathrm{~F} 1$ seedlings were distributed to 28 farmers for on-farm evaluation and twelve were selected and are under propagation. In Nigeria, 180 seedlings have been cloned and included in clonal evaluation trials. The seeds received have also been germinated and F1 hybrids are being evaluated.

In Indonesia, profuse natural seeds set occurred naturally among introduced genotypes and local cultivars. As various Diptera spp. are active pollinators, open pollinated seeds were produced. In the Philippines, the introduced genotypes have increased the number of potential parents for hybridization. Natural flowering occurred in SM115 and SM151 and they produced open pollinated seeds. Artificial induction of flowering had to be done as synchronization of flowering with local cultivars was a problem. In India, breeding was also hindered due to asynchrony in flowering and an attempt was made to cryostore pollen at different time intervals ranging from 1 week to 2 months and to use the cryostored pollen for hybridization with introduced genotypes. Fruit setting was observed within a week of crossing introduced genotypes with cryopreserved pollens (Mukherjee et al. 2016). Introduced genotypes were also crossed in Bhubaneswar (Orissa) and 31 crosses recombining TANSAO cultivars and Samoa hybrids were successful. The seeds of these 31 full-sib families were sent to VARTC in Vanuatu were they were germinated and 5214 hybrids were obtained and are now under selection. In Papua New Guinea, 57 genotypes were selected as parents for hybridizations, including 15 cultivars from the NARI core collection, 28 introduced genotypes, and 14 hybrids from the NARI breeding programme. Two hundred crosses were made of which $93 \%$ developed seeds and of these $60 \%$ germinated. Subsequently, over 4000 seedlings are now under selection in 46 progeny trials in Madang and Morobe provinces (northern coast of PNG).

In Vanuatu, controlled crosses were made to produce full sib families aimed at evaluating broad sense heritability and genetic gain for traits related to vegetative growth, yield, and corm quality. A fully randomized-block trial consisting of 13 full-sib families (2040 F1 hybrids) was established and measured in F1 (seminal generation) and first clonal generation (C1). Statistical tests revealed the stability of the presence or absence of stolons, suckers, and inflorescences between $\mathrm{F} 1$ and $\mathrm{C} 1$, suggesting strong genetic control for such traits. The number of stolons, the number of suckers, fresh corm weight, and dry matter content were found to be the most heritable traits, indicating that breeders should focus on those for 
eliminating undesirable hybrids in early clonal generations (Soulard et al. 2016).

\section{Discussion}

If climatic changes are going to cause the problems envisaged (severe droughts, heavy rains and/or development of pests and diseases), then breeding crops with wide genetic diversity is an appropriate approach to overcome the disasters that will otherwise ensue. The work described here has successfully broadened the genetic bases of taro in 14 countries through the introduction, on-station and on-farm evaluation of exotic germplasm. Country partners have conducted the first crosses and generated thousands of seedlings. These new genotypes have been screened, evaluated, and distributed to producers, representing an exceptional resource of genetic diversity. Also, partners started to exchange internationally seeds of taro and this is a major breakthrough as it is the first time in the history of Aroids research that it is done on such a large scale. This process has injected tremendous allelic diversity in different countries.

During this 6 years global experiment, we have shown that when introduced genotypes of taro satisfy famers' needs, they are readily adopted, although more time is obviously needed to confirm their final adoption. For subsistence farmers, quality taste criteria are always the most important for adopting new clones but farmers are also interested in variation and in new morphological traits (Camus and Lebot 2010). If the introduced genotypes continue to correspond to local agronomic expectations, and if their cooking properties, organoleptic qualities and texture remain acceptable over the next clonal generations, they will be propagated and shared with other communities. The more they are appreciated, the more they are propagated and exchanged with other farmers (Sardos et al. 2012). Several countries reported on-station theft of introduced genotypes before they could be distributed because of their attractive morphological appearance (e.g., red petioles or waxiness of leaf blades). Local adaptation and yield are, of course, also appreciated but their evaluation takes several clonal generations before it can be confirmed. In the present study, only 2 years of on-farm evaluation trials were conducted and it is too soon to conclude but it is possible to say that introductions had a significant impact on taro diversity as in all countries, except South Africa, cultivars or hybrids were selected.

Once parents are selected, the controlled crosses aim at producing the maximum number of seedlings for field evaluation. Unfortunately, around the world, the most interesting cultivars of $C$. esculenta do not flower naturally and it is necessary to induce flowering with gibberellic acid for breeding purposes. Detailed crossing protocols to assist taro breeders are now available (www.ediblearoids.org) but in some countries $\mathrm{GA}_{3}$ is difficult to find. Also, success rates in controlled crosses of taro are frequently very low (approx. 30\% of hand crosses produce seeds) and depending on the parents, the number of seedlings per cross may vary from 0 to 400 (Ivancic and Lebot 2000). In the present global experiment, all countries followed the same approach: identification of the best parents and induction of flowering. When successful controlled crosses were made with a low success rate but with sufficient number of hybrids (often several hundreds) (Table 4), the screening of hybrids was done using visual tools (e.g., presence or absence of suckers and stolons) to allow the rapid elimination of undesirable genotypes in the seminal (F1) and first clonal generation (C1).

More advanced breeding programmes in Samoa (Iosefa et al. 2012), Hawaii (Cho 2004) and PNG (Ivancic and Lebot 2000) have proceeded similarly for the last three decades and lessons have been learned for taro breeding. Selection is always made on the individual value of the parents. In Papua New Guinea, the breeding programme attempted to use a wild genotype from Thailand (called Bangkok) as a source of resistance to TLB (Singh and Okpul 2000). Unfortunately, it was soon evident that the incorporation of resistance brought along several deleterious traits, such as stolons and acridity. Now this programme and others are using tolerant parents to produce horizontal resistance. The present study has confirmed the validity of this approach with several PNG hybrids successfully selected in Costa Rica, Nicaragua, Cuba, St Vincent, Burkina Faso, Nigeria, and Vanuatu (Table 3). In Samoa, the breeding programme was initiated with the introduction of good (non-acrid) foreign cultivars resistant to TLB, first from Micronesia and then from SE Asia (TANSAO) and presenting significant genetic diversity (Kreike et al. 2004). Several selected hybrids were distributed and accepted by farmers (Fonoti 2005). 
The results obtained in the present global experiment indicate that the Samoan breeding programme has also been successful as many hybrids (SM genotypes) are now accepted by farmers in 14 countries. A similar approach was used in Hawaii and the introduction of TANSAO cultivars allowed the production of hybrids resistant to TLB. In this case again, taro breeding has been successful has demonstrated by the number of hybrids (HW genotypes) selected by farmers (Table 3).

However, in most countries there are still serious technical constraints needing solutions before taro improvement programmes can progress efficiently. The somewhat limited number of successful controlled crosses (Table 4) is impairing the creation of diversity needed for further selection but asynchrony, pollen viability and the receptiveness of female flowers are severely impacting the success rates of these crosses. Protocols for the cryopreservation of pollen, either freeze dried or cryostored in liquid nitrogen have been developed (Mukherjee et al. 2016) but more work is needed, especially with freeze dried pollen in order to ease and speed up the control crosses.

When several full-sib families are obtained there is then a need for robust field comparison and there is also a need for a field design able to control the environmental variance. If there are between 100 and 300 hybrids per family, the field experiment layout becomes fairly expensive to maintain. As taro breeders need efficient visual tools to screen thousands of seedlings successfully at the F1 and C1 stages (Ivancic et al. 2003), a Vegetative Growth Index (VGI) was developed to predict the final yield of hybrids during their vegetative phase (before 5 months). This multi criteria index combines the measurements of the number of suckers, stolons, the plant height, leaf length and width to predict the yield of the plant. The correlation analysis between individual plants in F1 and $\mathrm{C}$, has confirmed the suitability of VGI as a corm yield prediction tool for screening hundreds of hybrids (Soulard et al. 2016). In several countries (Madagascar, PNG, Vanuatu), the VGI has been shown to be a practical and efficient tool.

Field evaluation of hybrids is then constrained by the production of homogenised propagules: headsets of taro corms produce vigorous plants while young suckers and stolons do not. When evaluating new hybrids, it is observed that intraclonal variation is often very high between different propagules of the same clone (e.g., headset, suckers or stolons or cormels originating from the same clone). It is therefore difficult to obtain sufficiently homogenised planting materials to establish reliable field trials with the needed replications for accurate phenotyping. Hence, this physiological heterogeneity gives significantly different results during the first evaluation trials and is often confusing. The availability of sufficient homogenised planting materials (number of clones per genotype) impacts directly the reliability of the evaluation data because of the insufficient number of replications, the small plot sizes, and the small number of sites where these genotypes are evaluated. Also, the relatively long growth cycle for taro (8-10 months) is a potential source of errors when evaluating genotypes for yield and dry matter content as these two major traits can vary with the month of harvest.

Finally, G x E interactions necessitate the establishment of multi-locations trials but the constraints imposed by accurate evaluation are rendering this approach very complex (Ivancic and Lebot 2000). A way of coping with these practical and financial constraints is to work with farmers for the evaluation, as shown in the present study (Table 3). As diversity exists because of genetic resources distribution and adaptation by localized populations (Namkoong et al. 2004), the introduction of allelic diversity represents an attractive approach for strengthening farmers' adaptation if this diversity is adopted and used (Lebot et al. 2005). Farmers are often pushing crop populations through a new evolution, adding favourable alleles to the gene pool while maintaining diversity (Birnbaum 2006). Farmers often maintain landraces while adopting modern varieties (Brush 2000). They know how to manage their varietal portfolios to optimise risk management. If allelic diversity is introduced, farmers' capacity to adapt to forthcoming changes will be strengthened by the access to new diversity.

\section{Conclusions}

This global experiment was set out to develop a simple system for speeding up the improvement of neglected clonally propagated crops using taro as no one has the international mandate to work on this crop. To test the approach, this experiment shared germplasm of wide allelic diversity among 14 partners, evaluated and 
compared 50 introduced genotypes with local cultivars, gave the best selections to farmers for evaluation and initiated local breeding programmes. The approach was participatory, effectively distributing genotypes to farmers in the shortest time possible due to the time needed for bulking clonally the planting materials. In most participating countries it worked well, although there were obvious differences depending on the local means available. In order to strengthen smallholders' capacity to adapt to climatic changes, the global approach tested for taro could be used for other species, especially neglected ones such as minor yams (Dioscorea spp.) and aroids (Alocasia macrorrhyza, Cyrtosperma chamissonis, Xanthosoma saggitifolium). Plant breeding offers a solution to climate change adaptation but financial costs and the lack of research capacity are major constraints. On-farm evaluation and selection might represent a cost efficient approach.

Acknowledgements This research was financially supported by the Europe-Aid project "Adapting clonally propagated crops to climatic and commercial changes" (Grant No. DCI-FOOD/ 2010/230-267 SPC). Thanks are due to the 14 different countries technicians working on research stations and to farmers and their families for their enthusiastic contribution.

\section{Compliance with ethical standards}

Conflict of interest The authors declare that they have no conflict of interest.

\section{References}

Birnbaum K (2006) Crop genetics on modern farms: gene flow between crop populations. In: Motley TJ, Zerega N, Cross $\mathrm{H}$ (eds) Darwin's harvest: new approaches to the origins, evolution, and conservation of crops. Columbia University Press, New York, pp 333-346

Brush SB (2000) Genes in the field: on-farm conservation of crop diversity. Lewis Pubs, Boca Raton

Camus P, Lebot V (2010) On-farm assessment of clonal introduction of root crops diversity in Vanuatu, Melanesia. Exp Agric 46(4):541-559

Ceballos H, Kawuki RS, Gracen VE, Yencho GG, Hershey CH (2015) Conventional breeding, marker-assisted selection, genomic selection and inbreeding in clonally propagated crops: a case study for cassava. Theor Appl Genet 128:1647-1667

Chaïr H, Traoré RE, Duval MF, Rivallan R, Mukherjee A, Aboagye LM, Van Rensburg WJ, Andrianavalona V, Pinheiro de Carvalho MAA, Saborio F, Sri Prana M, Komolong B, Lawac F, Lebot V (2016) Genetic diversification and dispersal of taro (Colocasia esculenta (L.) Schott). PloS ONE 11(6):1-19

Cho JJ (2004) Breeding Hawaiian taros for the future. In: Guarino L, Taylor M, Osborn T (eds) Proceedings of the 3rd taro symposium held in Nadi, Fiji. Secretariat of the Pacific Community, pp 192-196

Dodd RS, Douhovnikoff V (2016) Adjusting to global change through clonal growth and epigenetic variation. Front Ecol Evol 4:86. doi:10.3389/fevo.2016.00086

FAO (2014) FAO Statistical database. www.fao.org visited Feb 2014

Fonoti P (2005) Breeding resistance to taro leaf blight (Phytophthora colocasiae) in Samoa. Masters of Crop Science Thesis, USP, Alafua, July, 2005

Fullagar R, Field J, Denham T, Lentfer C (2006) Early and mid Holocene tool-use and processing of taro (Colocasia esculenta), yam (Dioscorea sp.) and other plants at Kuk Swamp in the highlands of Papua New Guinea. J Archaeol Sci 33(1):595-614

Harding RM, Revil PA, Hafner GJ, Yang I, Maino MK, Devitt LC, Dowling ML, Dale JL (2004) Characterisation of taro viruses and the development of diagnostic tests. In: Guarino L, Taylor M, Osborn T (eds) Proceedings of the 3rd taro symposium held in Nadi, Fiji. Secretariat of the Pacific Community, pp 98-101

Iosefa T, Taylor M, Hunter D, Tuia V (2012) The taro improvement programme in Samoa: sharing genetic resources through networking. FAO RAP-NIAS: plant genetic resources in Asia and the Pacific: impacts and future. In: Proceedings of a symposium held in Tsukuba, Japan. 18th Oct 2011-FAO-p, pp 25-40

Ivancic A, Lebot V (2000) Taro (Colocasia esculenta): genetics and breeding. Collection "Repères", CIRAD, Montpellier, France

Ivancic A, Quero Garcia J, Lebot V (2003) Development of visual tools for selecting qualitative corm characteristics of taro (Colocasia esculenta (L.) Schott). Aust J Agric Res 54(6):581-588

Kreike CM, van Eck HJ, Lebot V (2004) Genetic diversity of taro, Colocasia esculenta (L.) Schott, in Southeast Asia and the Pacific. Theor Appl Genet 109:761-768

Lebot V, Aradhya M (1991) Isozyme variation in taro (Colocasia esculenta (L.) Schott) from Asia and Oceania. Euphytica 56:55-66

Lebot V, Gunua T, Pardales JR, Prana MD, Thongjiem MS, Viet NV, Yap TC (2004) Characterisation of taro (Colocasia esculenta (L.) Schott) genetic resources in Southeast Asia and Oceania. Genet Resour Crop Evol 51:381-392

Lebot V, Ivancic A, Abraham K (2005) The geographical distribution of allelic diversity, a practical means of preserving and using minor root crops genetic resources. Exp Agric 41:475-489

Matsuda M (2002) Taro, Colocasia esculenta (L.) Schott, in Eastern Asia: its geographical distribution and dispersal into Japan. Doctoral Thesis, Kyoto University, Kyoto, Japan

Matthews PJ, Lockhart PJ, Ahmed I (2017) Phylogeography, ethnobotany and linguistics issues arising from research on the natural and cultural history of taro, Colocasia esculenta (L.) Schott. Man India 97(1):353-380 
Mercer KL, Perales HR (2010) Evolutionary response of landraces to climate change in centers of crop diversity. Evol Appl 3:480-493

Mukherjee A, George J, Pillai R, Chakrabarti SK, Naskar SK, Patro R, Nayak S, Lebot V (2016) Development of taro (Colocasia esculenta (L.) Schott) hybrids overcoming its asynchrony in flowering using cryostored pollen. Euphytica 212(1):29-36

Namkoong G, Lewontin RC, Yanchuk AD (2004) Plant genetic resources management: the next investments in quantitative and qualitative genetics. Genet Resour Crop Evol 51:853-862

Omane E, Oduro KA, Cornelius EW, Opoku I, Akrofi A, Sharma K, Bandyopadhyay R (2012) First report of leaf blight of taro (Colocasia esculenta) caused by Phytophthora colocasiae in Ghana. Plant Dis 96(2):292

Ramirez-Villegas J, Challinor AJ, Thornton PK, Jarvis A (2013) Implications of regional improvement in global climate models for agricultural impact research. Environ Res Lett 8(2):024018

Roullier C, Benoit L, McKey D, Lebot V (2013) Historical collections reveal patterns of diffusion of sweet potato in Oceania obscured by modern plant movements and recombination. PNAS 110(6):225-2210

Sardos J, Noyer JL, Malapa R, Bouchet S, Lebot V (2012) Genetic diversity of taro (Colocasia esculenta (L.) Schott) in Vanuatu (Oceania): An appraisal of the distribution of allelic diversity (DAD) with SSR markers. Genet Resour Crop Evol 59(5):805-820

Scarcelli N, Tostain S, Vigouroux Y, Agbangla C, Dainou O, Pham JL (2006) Farmers' use of wild relative and sexual reproduction in a vegetatively propagated crop: the case of yam in Benin. Mol Ecol 15(9):2421-2431

Singh D, Okpul T (2000) Evaluation of 12 taro (Colocasia esculenta (L.) Schott) leaf blight resistant lines for yield and eating quality in Papua New Guinea. SABRAO J Breed Genet 32(1):39-45

Soulard L, Letourmy P, Cao TV, Lawac F, Chaïr H, Lebot V (2016) Evaluation of vegetative growth, yield and quality related traits in taro (Colocasia esculenta (L.) Schott). Crop Sci 56(3):976-989

Taylor MB (2002) The establishment of a regional germplasm centre in the Pacific island region. In: Engels JMM, Rao VR, Brown AHD, Jackson MT (eds) Managing plant genetic diversity. CAB International, Oxon, pp 104-112

Taylor MB, Tuia V, Sant R, Lesione E, Prasad R, Prasad RL, Vosaki A (2004) Using in vitro techniques for the conservation and utilization of Colocasia esculenta var. esculenta (taro) in a regional genebank. In: Guarino L, Taylor M, Osborn T (eds) Proceedings of the 3rd taro symposium held in Nadi, Fiji. Secretariat of the Pacific Community, pp 69-73

VandenBroucke H, Mournet P, Vignes H, Chair H, Malapa R, Duval MF, Lebot V (2015) Somaclonal variants of taro (Colocasia esculenta Schott) and yam (Dioscorea alata L.) are incorporated into farmers' varietal portfolios in Vanuatu. Genet Resour Crop Evol 63(3):495-511

Zettler FW, Jackson GVH, Frison EA (eds) (1989) FAO/IBPGR technical guidelines for the safe movement of edible aroid germplasm. Food and Agriculture Organization of the United Nations, Rome/International Board for Plant Genetic Resources, Rome 